\title{
Rainfall analysis in the northern region of Peninsular Malaysia
}

\author{
A. H. Syafrina ${ }^{1, *}$, A. Norzaida ${ }^{2}$, O. Noor Shazwani ${ }^{2}$ \\ 1Department of Science in Engineering, Kuliyyah of Engineering, International Islamic University of Malaysia, 53100 Gombak, \\ Selangor, Malaysia \\ ${ }^{2}$ UTM Razak School of Engineering and Advanced Technology, Universiti Teknologi Malaysia, Jalan Sultan Yahya Petra, 54100 \\ Kuala Lumpur, Malaysia
}

\section{ARTICLE IN F O}

Article history:

Received 14 July 2017

Received in revised form

15 September 2017

Accepted 16 September 2017

\section{Keywords:}

Extreme

Gamma

Rainfall intensity

Weather generator

Weibull

Goodness of fit

\begin{abstract}
A B S T R A C T
Modeling of rainfall is important for assessing the possible impacts of climate change. To achieve accurate projections of rainfall events, availability of sufficient hydrological station data is critical. Precipitation is one of the most important meteorological variables for hydrological modeling. In cases where long series of observed precipitation are not available, they can be stochastically generated by weather generators. Advanced Weather Generator (AWE-GEN) has been proven to generate precipitation data at the temperate climate regions with Gamma distribution being incorporated in the model to represent rainfall intensity. However, in a tropical climate such as Malaysia, some studies disputed the incorporation of Gamma distribution. As such, in this study, Weibull a heavy tail distribution is proposed to be used. The AWE-GEN has well performed in the wetter region such as the eastern of the peninsular. However, rainfall distribution within Peninsular Malaysia is highly variable temporally and spatially. The northern region is drier especially during the southwest monsoon season. This region receives minimal rain during the northeast monsoon due to the presence of the Titiwangsa Range which obstructs the region from getting rain by the north easterly winds. Therefore, the objectives of the study are two-fold. First, this study compares the performance of Gamma and Weibull that are incorporated in the AWE-GEN in simulating rainfall series for the northern region of the peninsular. Second, the monthly rainfall and the extreme rainfall series are simulated using the better distribution. The performances of Gamma and Weibull distributions are compared using the goodness of fit test, Root Mean Square Error (RMSE). Results showed that Gamma is the better distribution in simulating rainfall at rainfall stations located at the outer parts of the northern coast whereas Weibull is the better distribution for stations located in the interior parts of the northern coast. Hourly and daily extreme rainfalls seem to be well captured at all stations. Similarly, wet spell length is well simulated while in contrast, dry spell length is slightly underestimated at all stations. Overall, Gamma and Weibull produce commendable results in simulating extreme rainfall as well as wet spell length throughout the northern region of the peninsular.
\end{abstract}

(C) 2017 The Authors. Published by IASE. This is an open access article under the CC BY-NC-ND license (http://creativecommons.org/licenses/by-nc-nd/4.0/).

\section{Introduction}

Climate change is no longer a distant threat. Observation evidence such as floods, major storm surges, hurricanes, prolong droughts and forest fires is a constant reminder that climate change is taking place. Water resources, agriculture, infrastructure, public health and economic activities face severe

\footnotetext{
* Corresponding Author.

Email Address: syafrinaabdulhalim@iium.edu.my (A. H. Syafrina) https://doi.org/10.21833/ijaas.2017.011.002

2313-626X/C 2017 The Authors. Published by IASE.

This is an open access article under the CC BY-NC-ND license

(http://creativecommons.org/licenses/by-nc-nd/4.0/)
}

impacts caused by the changing climate. Human actions such as fossil fuel combustion, agricultural activities and land use, are altering the composition of atmospheric concentrations of greenhouse gases. Many world's climate scientists consider this greenhouse effect contributed significantly to the increase of earth's temperature. The global warming impacted many natural systems, which include increase of average air and ocean temperatures, widespread melting of snow and ice and rising global average sea level (Tangang et al., 2012), changes in rainfall regime and increase the risks of flooding (Huang et al., 2011; Willems et al., 2012). The notable changes observed in marine and freshwater 
ecosystems, are also related to changes in temperature.

Among the major impacts of global warming are the increased frequency and intensity of extreme rainfall events (Cheng et al., 2012; Sen Roy, 2009). Extreme rainfall is one of the main causes of natural disasters such as flooding and landslide incidences. Therefore, it is imperative that substantial attention be paid to the modeling of extreme rainfall events. To date, there are considerable studies emphasizing on extreme rainfall events for preventive measures of massive flooding occurrences as well as for projecting future extreme rainfall (Chu et al., 2012). This has led to numerous collaborations between meteorologists and hydrologists to establish a hydrological model of spatial and temporal precipitation extremes. Around the globe, the frequency of heavy precipitation events is found to significantly escalating in the eastern regions of North and South America, northern Europe, and northern and central Asia, while precipitation declined in the Sahel, the Mediterranean, southern Africa, and parts of southern Asia between 1900 and 2005 (IPCC, 2007; Zin et al., 2010).

This is also true for Malaysia, which experiences changes in rainfall regimes. Although Malaysia is considered to be less prone to natural disasters, Malaysia remains vulnerable to climate change and natural disasters due to the increase in climaterelated extremes events (Suhaila et al., 2010). Among the most common natural disasters in Malaysia are flood and landslide. Since both of these events are related to extreme rainfall, accurate projections of rainfall events are very much vital for mitigation and preparedness purposes. To achieve accurate projections of rainfall events, availability of sufficient hydrological station data is critical. Precipitation is one of the most important meteorological variables for hydrological modeling. In cases where long series of observed precipitation are not available, they can be stochastically generated by weather generators. Advanced Weather Generator (AWE-GEN) has been proven to be able to generate precipitation data at wetter region of Peninsular Malaysia such as east coast region. Hence, the aim of this study is to test the performance of AWE-GEN at semi-arid (drier) region.

The northern region is the driest region especially during the southwest monsoon season. This region receives minimal rain during the northeast monsoon due to the presence of the Titiwangsa Range which obstructs the region from getting rain by the north easterly winds (Syafrina et al., 2015). The southwest monsoon has generally lower wind speeds compared to the northeast monsoon because the winds during the southwest monsoon which originated from Sumatera, are 'soften' by the high mountain ranges in Sumatra. As a result, the west coast as well as the north coast of the Peninsular experience drier period. Geographically, the northwest zone has a relatively flat topography separated from the rest of the region by high and rough terrains in the northern parts of Peninsular Malaysia (Wong et al., 2016).

Therefore, the objectives of the study are twofold. First, this study tests the performance of Gamma and Weibull that are incorporated in the weather generator in simulating rainfall series for the northern region of Peninsular Malaysia. Second, the monthly rainfall and the extreme rainfall will be simulated using the best distribution. Description of data is given in Section 2. The methodology used in the study is discussed in Section 3. Results are analysed in Section 4 and finally, the analysis of the results is be summarized.

\section{Data}

Peninsular Malaysia is located between $1^{\circ}$ and $6^{\circ}$ $\mathrm{N}$ in the northern latitude and between $100^{\circ}$ to $103^{\circ}$ E longitude. The surface climate is influenced by the northeast monsoon season between November and February and by southwest monsoon season between May and August. The northeast monsoon season is usually associated with heavier rainfall with the eastern and southern regions being the most affected areas. In between these two monsoons are the inter-monsoon seasons occurring in MarchApril (MA) and September-October (SO), which bring intense convective rainfall to the western coast of Peninsular Malaysia.

In this study, the AWE-GEN model is developed based on 30 years of historical data (1975-2005) namely hourly rainfall, hourly temperature, hourly relative humidity and hourly wind speed. Hourly rainfall data were sourced from the Malaysian Drainage and Irrigation Department (DID) while other meteorological data were sourced from the Malaysian Meteorological Department (MMD). Five rainfall stations located in the northern region were selected for further analysis. Fig. 1 shows the location of the rainfall stations while Table 1 gives the latitude and longitude for each rainfall station.

\section{Methodology}

In this study, both Gamma and Weibull distributions are individually fitted to the intensity of rainfall at the five chosen stations in the northern region of the Peninsular. Intra-annual variability of rainfall in AWE-GEN is represented by the NeymanScott Rectangular Pulses (NSRP) model, a stochastic based model which has shown to be capable of replicating rainfall series in Malaysia (Norzaida et al., 2016; Abas et al., 2014). The Gamma distribution that is associated in NSRP is shown below:

$$
P(x)= \begin{cases}\frac{1}{\Gamma(\alpha) \theta^{\alpha}} x^{\alpha-1} e^{\left(\frac{-x}{\theta}\right)} & , x>0 \\ 0 & , x \leq 0\end{cases}
$$

where $\theta$ is the scale parameter $(\theta>0), \alpha$ is the shape parameter $(\alpha>0)$ and $x$ is the hourly rainfall amount. Meanwhile, the Weibull distribution is as follows: 
$P(x)=\left(\frac{\beta}{\alpha}\right)\left(\frac{x}{\alpha}\right)^{\beta-1} \exp ^{\left(-\left(\frac{x}{\alpha}\right)^{\beta}\right)}$

where $\alpha$ and $\beta$ are the scale and shape parameters, respectively.

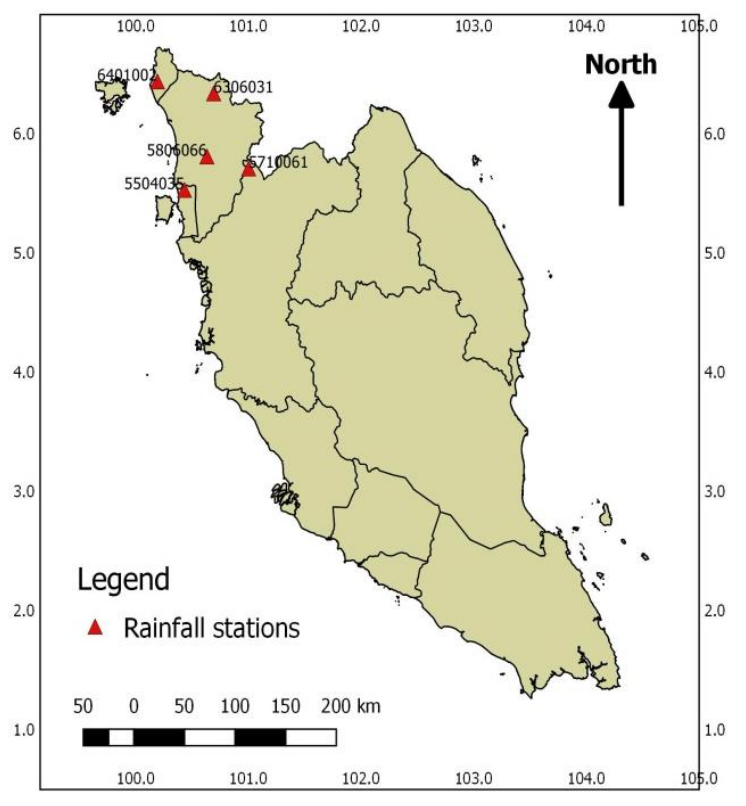

Fig. 1: Location of rainfall stations

Table 1: Latitude (lat) and Longitude (lon) of Stations

\begin{tabular}{ccc}
\hline Stations (part) & Lat $\left({ }^{\circ}\right)$ & Lon $\left({ }^{\circ}\right)$ \\
\hline 5504035 (outer) & 5.53 & 100.43 \\
5710061 (inner) & 5.71 & 101.00 \\
5806066 (inner) & 5.81 & 100.63 \\
6306031 (inner) & 6.34 & 100.69 \\
6401002 (outer) & 6.44 & 100.19 \\
\hline
\end{tabular}

Simulations of hourly rainfall series of thirty years are conducted individually using Gamma and Weibull distributions representing rainfall intensity at each of the five stations. In order to compensate for rainfall seasonality throughout the year, the simulation is conducted for each month. For the validation purposes, the simulated hourly rainfall series was divided into two non-overlapping periods of i) 1975 to 1989 and ii) 1990 to 2005. The 1975 to 1989 period was used as the reference period where the multiplicative factor was calculated based on the simulation output and the high resolution observational data. The changing factors were then used to improve the biases of the simulation output from 1990 to 2005. The improved version of hourly rainfall series was then compared to the observed series from the identical period of 1985-1999. In order to assess the performance of both distributions, Root Mean Square Error (RMSE) value was estimated for both sets of simulation. Lowest value of RMSE indicates better distribution at a particular station. Based on the comparison results at each station, the selected distribution is then used to simulate hourly rainfall series of thirty years.

\section{Results and discussions}

Table 2 shows the RMSE values between Gamma and Weibull distributions. It can be seen that Gamma is the better distribution in simulating rainfall at rainfall stations located at the outer parts of the northern coast whereas Weibull is the better distribution for stations located in the interior parts of the northern coast. Stations' locations are given in Fig. 1 previously. Next, hourly rainfall series were simulated at each station using the designated distribution for each calendar month. The simulated result for each month is then being summarize into a boxplot. Graphs for each station as given in Fig. 2, show the simulated series (green boxplot) against the observed series (red line graph). Generally the performance of the model at each station is quite good in mimicking the observed rainfall series. The mean of rainfall is simulated very well. The peak rainfall amount is in October (300-500 mm). Starting from November until February (i.e. northeast monsoon), the rainfall reaches the minimum level with a mean rainfall amount of $50 \mathrm{~mm}$ and continues to rise in April/May (250-350 mm) at all stations. This is consistent with Wong et al. (2016), where the study delineates this region based on the characteristics of rainfall. The northern region experiences a bimodal annual rainfall distribution. The primary peak during the autumn transitional period in October is higher compared to intermonsoon season. The primary monthly rainfall peak drops dramatically and reaches the minimum level in January. Rainfall amount continues to increase in March/April (inter-monsoon) and this continues from May to August (i.e. southwest monsoon) until the rainfall reaches the maximum level in October. This is also found in Syafrina et al. (2015) and Wong et al. (2016).

Table 2: RMSE values for Gamma and Weibull distributions at rainfall stations

\begin{tabular}{ccc}
\multicolumn{3}{c}{ distributions at rainfall stations } \\
\hline Station & RMSE (Gamma) & RMSE (Weibull) \\
5504035 (outer) & $250.2^{*}$ & 251.0 \\
5710061 (inner) & 229 & $212^{*}$ \\
5806066 (inner) & 238.6 & $228.3^{*}$ \\
6306031 (inner) & $238.7^{*}$ & 240 \\
6401002 (outer) & 667.2 & $590^{*}$ \\
\hline
\end{tabular}

Note: bold font and * indicate lowest RMSE values

Fig. 3 shows the simulation of extreme rainfall and wet/dry spell lengths for all stations. Both hourly and 24-hour extreme rainfall seems to be well captured by the model. Meanwhile, dry spell length is slightly underestimated at all stations except for station 6207032, whereas wet spell length seems to be well simulated at all stations except for stations 5806066 and 6306031. In the 30-year return period, the range of hourly extreme rainfall amount is between 100 and $200 \mathrm{~mm}$ while the range of 24hour extreme rainfall amount is between $350-450$ $\mathrm{mm}$. The northern region experiences 24-hour extreme rainfall during the northeast monsoon season and in March/April (inter-monsoon season). Such results help explain the episodes of massive floods in non-urban areas like the north coast. However, it is interesting to note that the northern region experiences both hourly and 24-hour extreme rainfall during the southwest monsoon season and in 
September/October (inter-monsoon season) where this region receives the highest rainfall during these

(i) Station 5504035

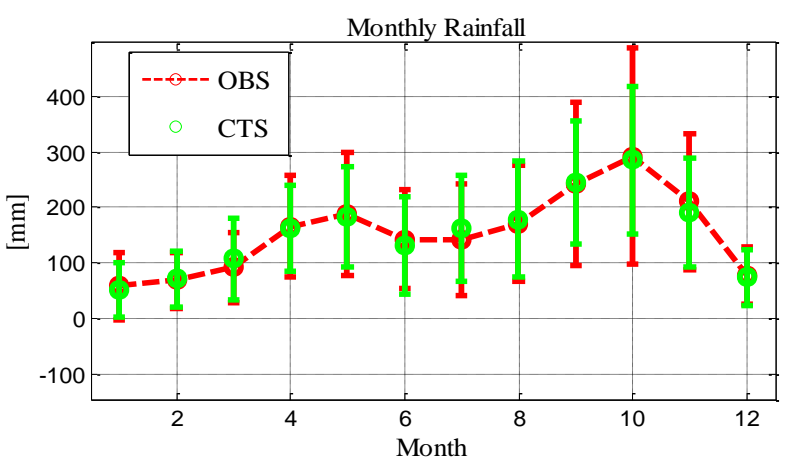

(iii) Station 5806066

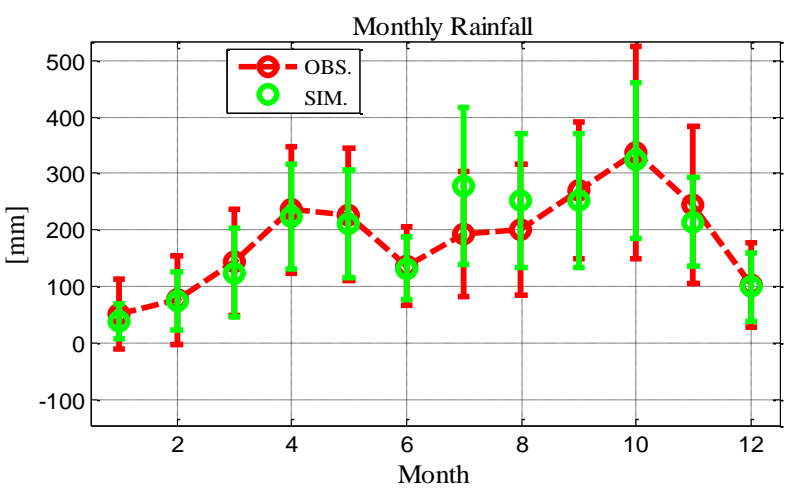

(v) Station 6306031

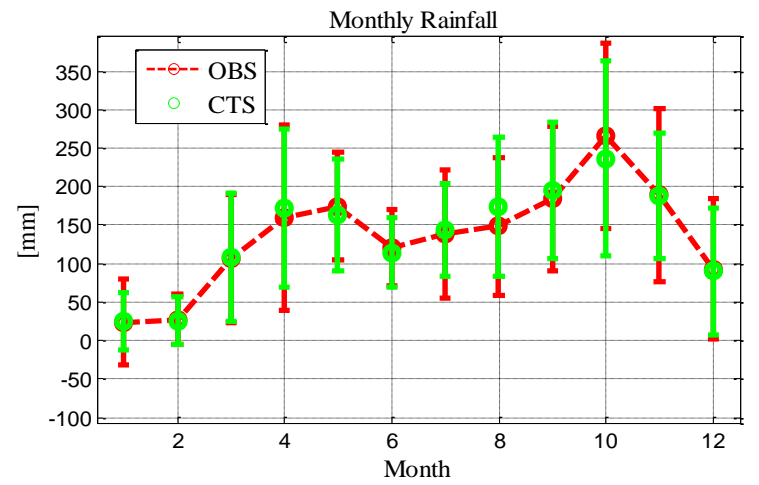

two seasons (Syafrina et al., 2015).

(ii) Station 5710061

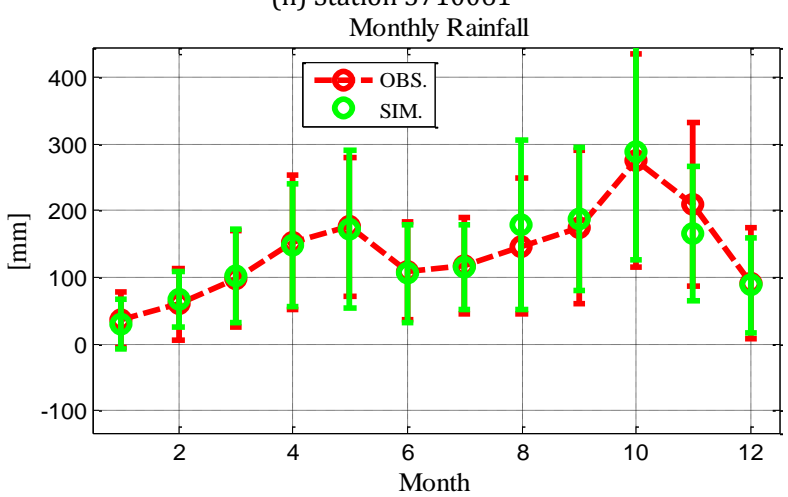

(iv) Station 6207032

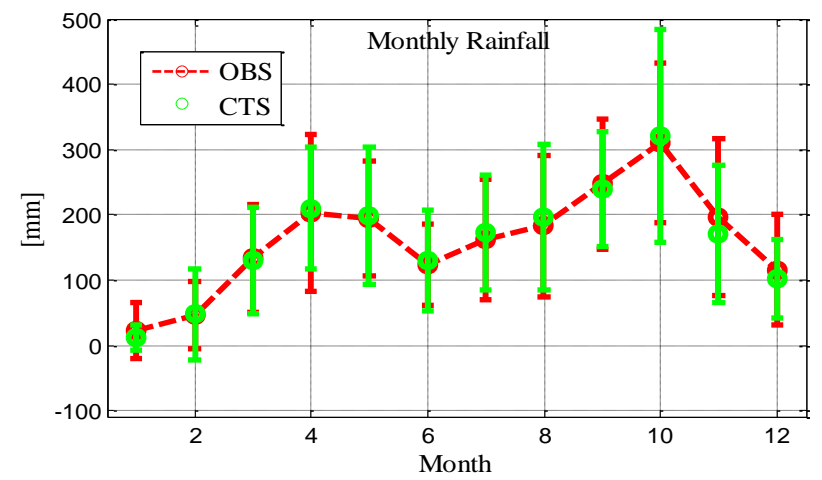

(vi) Station 6401002

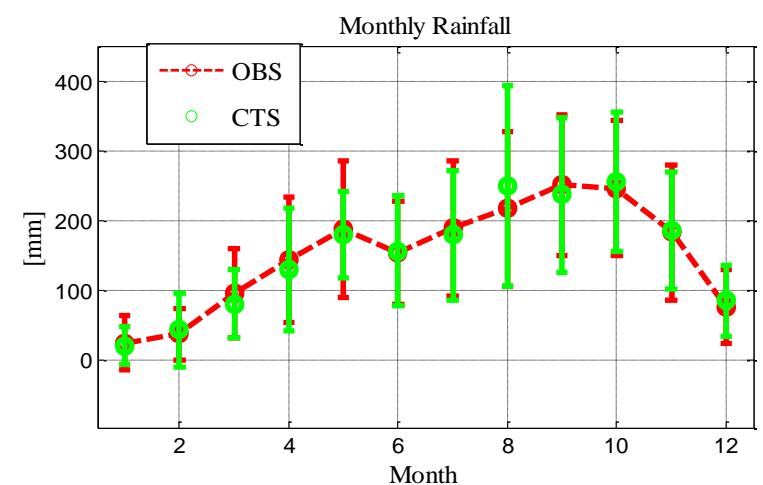

Fig. 2: Monthly rainfall at each station

(i) Station 5504035

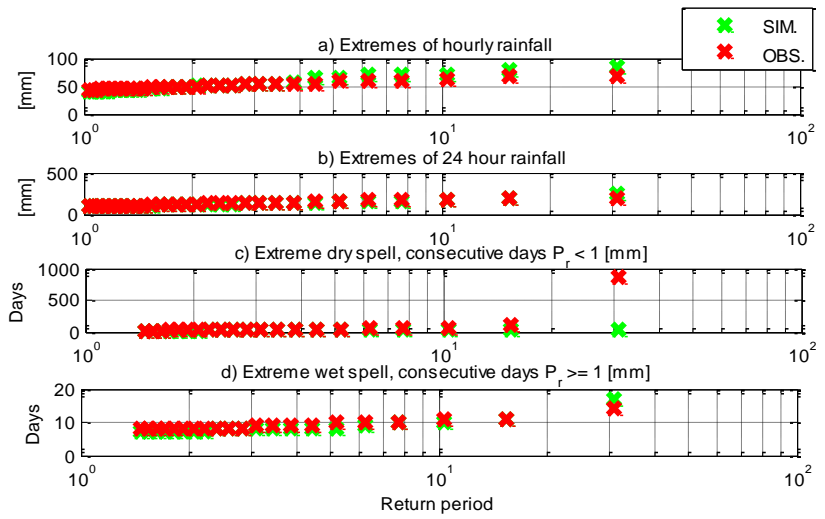

(iii) Station 5806066 (ii) Station 5710061
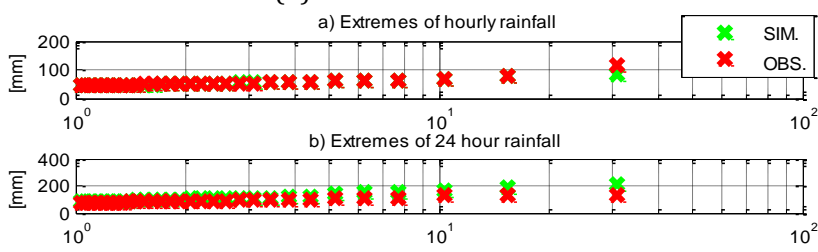

c) Extreme dry spell, consecutive days $P_{r}<1[\mathrm{~mm}]$

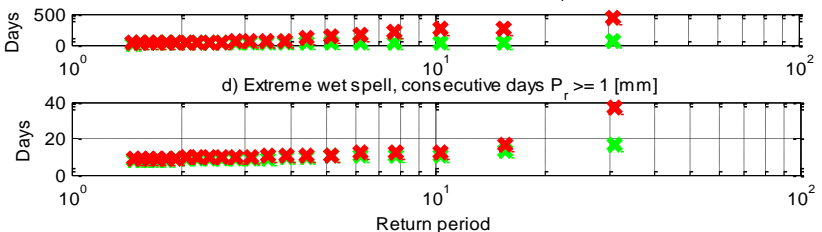

(iv) Station 6207032 


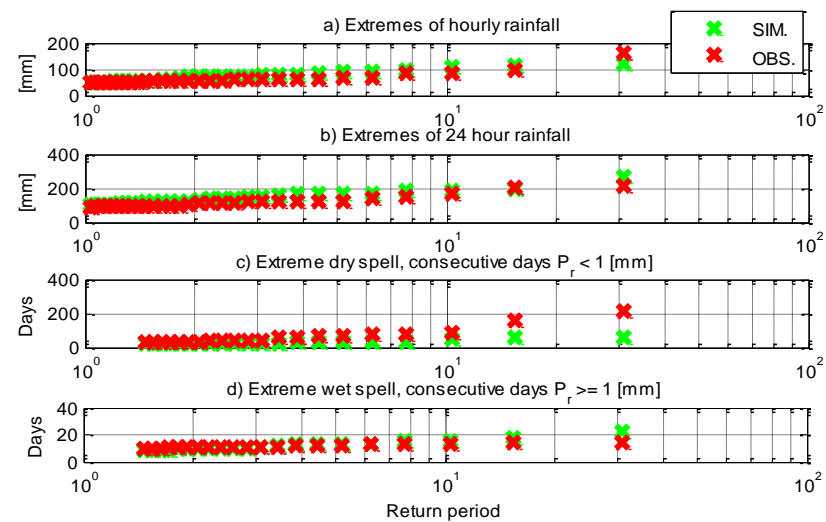

(v) Station 6306031
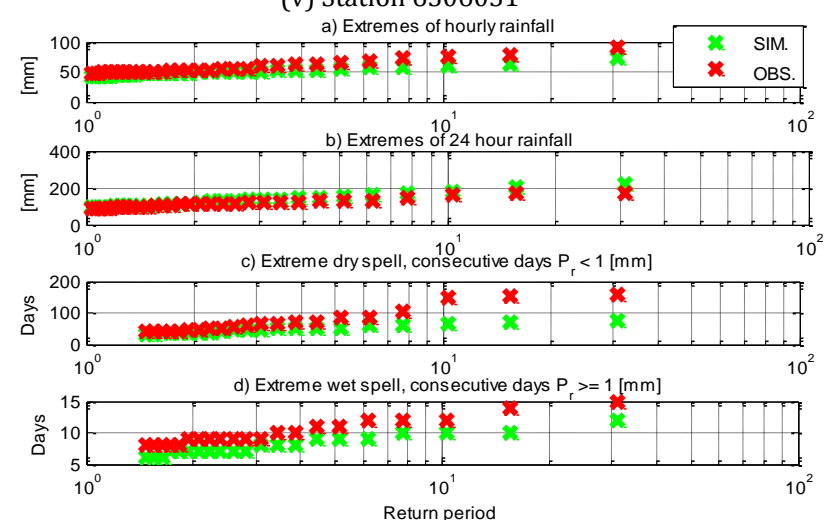

Fig. 3: Extremes rainfall (a) hourly (b) 24 hour and extremes
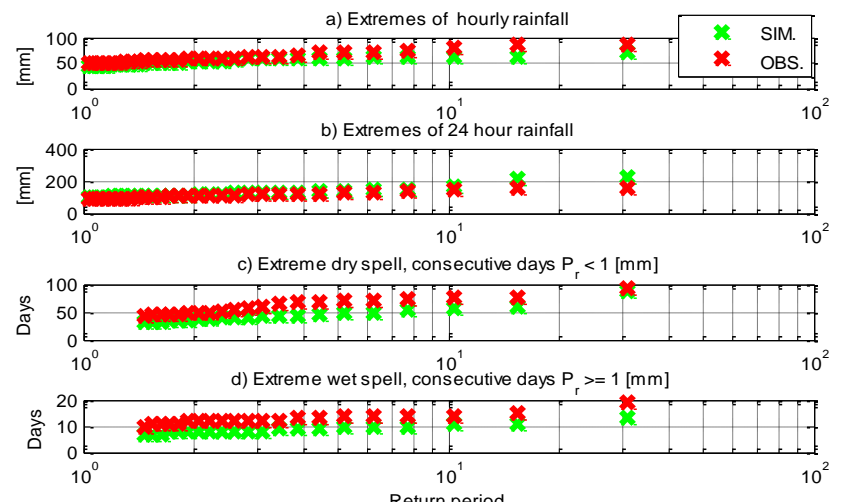

(vi) Station 6401002

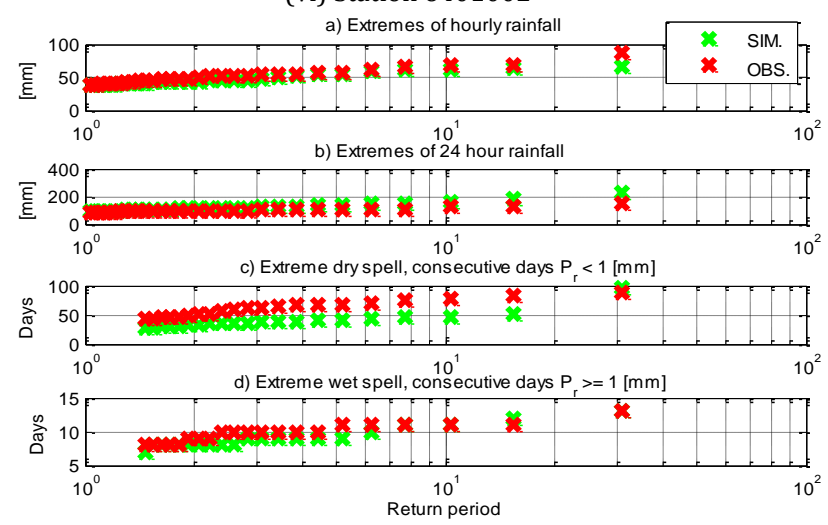

es spell length (c) dry consecutive days and (d) wet consecutive days

\section{Conclusion}

Malaysia experiences tropical climate with high rainfall variability. Extreme rainfall events tend to be related to many incidents of natural disasters, hence it is imperative that appropriate rainfall model is employed in generating reliable rainfall series. Simulated series could be valuable asset to variety of hydrological models. This study aims at identifying the best distribution in representing rainfall intensity of a weather generator model in the northern region, a drier region of Peninsular Malaysia. Results show that the performance of Gamma and Weibull distributions differ according to locations. Gamma is found to be the better distribution in simulating rainfall at stations located at the outer parts of the northern coast whereas Weibull is the better distribution for stations located in the interior parts of the northern coast. Both distributions seem capable of simulating extreme rainfall in the northern coast of Peninsular Malaysia despite some under/overestimating the wet spell and dry spell lengths. The rainfall in October contributes most of the annual rainfall followed by the one in May. It is noted that October and May are the beginning of the inter-monsoon and southwest monsoon, respectively. The monsoon conditions have different effects on the rainfall distribution in this region. This region is also less influenced by the northeast monsoon in which this region receives the minimum amount of rainfall, especially in January. Overall, Gamma and Weibull produce commendable results in simulating extreme rainfall as well as wet spell length in a drier region such as the northern region of the Peninsular.

\section{Acknowledgement}

We thank the Drainage and Irrigation Department for the rainfall data and IIUM and UTM for supporting this research. This research is funded by the Research Initiative Grant Scheme (Project ID: RIGS16-079-0243) and UTM GUP Vote $11 \mathrm{H} 63$.

\section{References}

Abas N, Daud ZM, and Yusof F (2014). A comparative study of mixed exponential and Weibull distributions in a stochastic model replicating a tropical rainfall process. Theoretical and Applied Climatology, 118(3): 597-607.

Cheng CS, Auld H, Li Q, and Li G (2012). Possible impacts of climate change on extreme weather events at local scale in South-Central Canada. Climatic Change, 112(3-4): 963-979.

Chu HJ, Pan TY, and Liou JJ (2012). Change-point detection of longduration extreme precipitation and the effect on hydrologic design: A case study of South Taiwan. Stochastic Environmental Research and Risk Assessment, 26(8): 11231130.

Huang CY, Wong CS, and Yeh TC (2011) Extreme rainfall mechanisms exhibited by Typhoon Morakot (2009). Terrestrial Atmospheric and Ocean Sciences, 22(6): 613-632.

IPCC (2007). Climate change 2007: The physical science basis. Summary for Policymakers, Contribution of Working Group I to the Fourth Assessment, Intergovernmental Panel on Climate Change, Geneva, Switzerland.

Norzaida A, Zalina MD, and Fadhilah Y (2016). Application of Fourier series in managing the seasonality of convective and 
monsoon rainfall. Hydrological Sciences Journal, 61(10): 1967-1980.

Sen Roy S (2009). A spatial analysis of extreme hourly precipitation patterns in India. International Journal of Climatology, 29(3): 345-355.

Suhaila J, Deni SM, Zin WWZ, and Jemain AA (2010). Trends in peninsular Malaysia rainfall data during the Southwest Monsoon and Northeast Monsoon seasons: 1975-2004. Sains Malaysiana, 39(4): 533-542.

Syafrina AH, Zalina MD, and Juneng L (2015). Historical trend of hourly extreme rainfall in Peninsular Malaysia. Theoretical and Applied Climatology, 120(1-2): 259-285.
Tangang FT, Juneng L, Salimun E, Sei KM, Le LJ, and Muhamad H (2012). Climate change and variability over Malaysia. Sains Malaysiana, 41(11): 1355-1366.

Willems P, Arnbjerg-Nielsen K, Olsson J, and Nguyen VTV (2012). Climate change impact assessment on urban rainfall extremes and urban drainage: Methods and shortcomings. Atmospheric Research, 103: 106-118.

Wong CL, Liew J, Yusop Z, Ismail T, Venneker R, and Uhlenbrook S (2016). Rainfall characteristics and regionalization in Peninsular Malaysia based on a high resolution gridded data set. Water, 8(11): 500-516.

Zin WZW, Jamaludin S, Deni SM, and Jemain AA (2010). Recent changes in extreme rainfall events in Peninsular Malaysia: 1971-2005. Theoretical and Applied Climatology, 99(3-4): 303-314. 